\title{
A produção de significados na elaboração escrita em língua inglesa na atividade social: participação de Pen-pal
}

Ana Laura Hoffart ${ }^{1}$

Daniela A. Vendramini Zanella²

\begin{abstract}
RESUMO: Este trabalho tem como objetivo analisar a produção de significados na elaboração escrita em língua inglesa dos alunos de uma escola pública a partir do desenvolvimento de atividades criadas por esta educadora no PIBID-LI/UNISO ${ }^{3}$. O estudo fundamenta-se em conceitos sobre o ensino-aprendizagem de língua inglesa por meio de Atividade Social (LIBERALI, 2009), o brincar na concepção vygotskyana (HOLZMAN, 2009) e atividade criadora (VYGOTSKY, 1930/1987). A análise é desenvolvida a partir de excertos advindos da elaboração escrita em língua inglesa dos alunos do $8^{\text {o }}$ ano de uma escola pública. A metodologia é de Pesquisa CríticoColaborativa - PCcol (MAGALHÃES, 2009). Os excertos são discutidos a partir de categorias argumentativas que centralizam os aspectos enunciativo-discursivolinguísticos (Liberali, 2013, apud VENDRAMINI ZANELLA, 2013) e interpretados mediante o aporte teórico apresentado neste trabalho. A partir da elaboração dos alunos, constata-se as dificuldades enfrentadas, além da produção de significados e da importância dos instrumentos multimodais para tornar o estudo da língua inglesa atrativo.
\end{abstract}

Palavras-chave: Língua inglesa. Atividade Social. Produção de significado. Multimodalidade.

\section{The production of meaning in written assignments in english within social activity: a Pen-pal participacion}

\footnotetext{
${ }^{1}$ Graduanda em Letras Português/Inglês pela Universidade de Sorocaba e bolsista do projeto na subárea de Língua Inglesa - Pibid/Capes/Uniso. E-mail: laura.analaura@hotmail.com

\begin{abstract}
${ }^{2}$ Daniela Aparecida Vendramini Zanella é mestre em Educação pela Universidade de Sorocaba (2003) e doutora em Linguística Aplicada e Estudos da Linguagem pela Pontifícia Universidade Católica de São Paulo (2013). Atualmente é professora titular do curso de Letras Português e Inglês da Uniso e leciona disciplinas de ensino-aprendizagem de língua inglesa e literatura estrangeira. Coordena o grupo "Tempo de Aprender"(Uniso) que visa à formação críticocriativa de professores de língua inglesa e o PIBID Capes da Uniso, subárea: inglês. É integrante do grupo de pesquisa LACE - Linguagem e Atividade em Contexto Escolar.
\end{abstract}

${ }^{3}$ Agradecemos à CAPES pelo apoio financeiro. 
ABSTRACT: This study aims to analyze the meaning production of the public school students when creating English language written texts from activities developed by this educator at PIBID-LI/ UNISO. The study is theoretically based on concepts of teaching-learning through Social-Activity (Liberali, 2009), the Vygotsky's concept of playing (HOLZMAN, 2009) and creative activity (VYGOTSKY, 1930/1987). The analysis is developed based on excerpts chosen from the 8th grade students' English language written elaboration and it is theoretically and methodologically grounded in Critical-Collaboration Research (MAGALHÃES, 2009). The excerpts are discussed from argumentative categories that centralize the enunciative-discursive-linguistic aspects (Liberali, 2013 apud VENDRAMINI ZANELLA, 2013) and interpreted from the theoretical framework presented in this paper. It was possible to verify the difficulties faced by the students on their written production, the meaning production and the importance of the multimodal environments to turn the English study attractive.

Key-words: English language. Social Activity. Knowledge production. Multimodality.

\section{Introdução.}

O grupo PIBID-Língua Inglesa/UNISO (PIBID- LI/ UNISO doravante) é formado por dez educadores que cursam o curso de Letras, uma educadora coordenadora e uma educadora supervisora da escola pública na qual o projeto é desenvolvido. Os educadores trabalham em grupos e agem em prol do desenvolvimento de propostas de ensino-aprendizagem por meio da Atividade Social. Essas elaborações apresentam-se embasadas teoricamente em Schneuwly \& Dolz (2004), que defendem a utilização de gêneros no ensino-aprendizagem de língua inglesa e em Liberali (2009), que discute a organização curricular de ensino-aprendizagem de língua inglesa por meio de Atividade Social. O conceito de Atividade Social preconiza que um conjunto de ações mobilizadas por um grupo com objetivos em comum satisfaz necessidades dos sujeitos na “vida que se vive" (MARX; ENGELS, 1845-46/2006, apud LIBERALI, 2009). O grupo PIBID- LI/UNISO compreende o brincar em uma perspectiva vygotskyana (HOLZMAN, 2009) para estimular a imaginação e possibilitar a interpretação de papéis sociais antes de realmente assumi-los socialmente. 
A escola pública mencionada neste estudo recebe alunos do $5^{\circ}$ ao $9^{\circ}$ ano do ensino fundamental dois e é a primeira na cidade de Sorocaba a assumir o modelo de educação ensino integral.

Diferentemente das escolas de tempo integral, cuja proposta é estender a jornada de estudo, a escola de ensino integral propõe que o aluno se desenvolva em sua totalidade (moral, social e culturalmente). $\mathrm{O}$ ensino integral reorganiza espaços e conteúdos para que a escola seja um local para esse desenvolvimento. O objetivo principal do ensino integral:

é atuar como fonte de inovação, introduzindo mudanças, através do estabelecimento de práticas pedagógicas no conteúdo, método e gestação sintonizados com as demandas relativas ás suas necessidades e interesses no que se refere ao seu projeto de vida, tendo como consequência o seu Protagonismo Juvenil (SEE, 2012).

Quinzenalmente, o grupo PIBID-LI/UNISO realiza reuniões de formação com a coordenação para alinhamento de projetos e estudos coletivos. Em uma das discussões, a educadora supervisora expôs o desejo de utilizar os computadores (netbooks) disponíveis na instituição com mais frequência, pois percebia o maior engajamento e interesse dos alunos nas aulas em que os netbooks eram utilizados. Entretanto, a supervisora desconhecia formas de agregar a tecnologia em sala de aula. Por esse motivo, solicitou ao grupo de educadores ideias que colaborassem para maior utilização do instrumento.

A partir da questão trazida pela supervisora, desenvolvi, sob a orientação da coordenadora, a proposta de ensino-aprendizagem de língua inglesa por meio da Atividade Social: participar de um Pen-pal. Para tanto, dispus um domínio virtual multimodal no qual os alunos do oitavo ano puderam se comunicar com estrangeiros para então postar as atividades realizadas em sala de aula como textos, brincadeiras e outros para compartilhar e demonstrar como é o cotidiano escolar deles. 
O presente trabalho tem como objetivo analisar a produção de significados na elaboração escrita em língua inglesa dos alunos do $8^{o}$ ano de uma escola pública a partir do desenvolvimento de atividades elaboradas por esta educadora no projeto PIBID-LI/UNISO. A proposta para o desenvolvimento dessa elaboração escrita buscava compreender se os alunos, ao entrarem em contato direto com a Língua Inglesa por meio de tecnologia, conseguiriam entender com mais facilidade o novo idioma e se o desejo pelo ensino-aprendizagem aumentaria quando o currículo escolar passasse a ser trabalhado de forma mais próxima ao cotidiano do jovem. Esses textos, elaborados pelos alunos, integraram-se às atividades solicitadas pela proposta de ensino-aprendizagem por meio da Atividade Social: participar de um Penpal, postados em blog.

Ainda no presente trabalho, estuda-se de que forma os ambientes multimodais aplicados simultaneamente como instrumentos aos Parâmetros Curriculares Nacionais (BRASIL, 1998) podem atrair os alunos no ensinoaprendizagem de língua inglesa, desvinculando a associação de internet apenas ao lazer. Dessa forma, a internet pode também ser entendida como ampliação de fronteiras culturais e de conhecimentos. Ademais, configura-se como instrumento para aproximação do educador e escola ao cotidiano do aluno.

Nos documentos oficiais (SEE, 2008) direcionados ao $8^{\text {o }}$ ano, havia a discussão sobre a cultura de outros países. Com base nesses parâmetros, a proposta de ensino-aprendizagem por meio da Atividade Social: participar de um Pen-pal foi escolhida por acreditar-se que dessa forma os alunos poderiam vivenciar as culturas e aprender a língua inglesa de maneira mais atrativa. Define-se Pen-pal pela comunicação por meio de cartas ou emails com pessoas de outros países, sem precisar realmente encontrá-las (CAMBRIDGE DICTIONARY, 2015). Essa prática é muito utilizada para aprender uma nova língua e conhecer outras culturas. 
Todas as quintas-feiras, durante a aula de língua inglesa do $8^{\underline{0}}$ ano, diversos emails, vídeos e discussões de jovens voluntários de diferentes países (Grécia, Califórnia e Taiwan) foram apresentados aos alunos. Durante as conversas sobre o material apresentado em sala de aula, os alunos expressaram o desejo de escrever e produzir respostas aos contatos, pois acreditavam que da mesma forma que eles não sabiam da realidade desses lugares, os jovens voluntários também não sabiam da realidade brasileira. O desejo por aprender a escrever uma resposta ao amigo virtual foi crucial para o sucesso da elaboração escrita, de forma que todos conseguiram produzir um pequeno texto contando sobre seu cotidiano e a vida no Brasil.

Nesse contexto, a tecnologia e o brincar colaboraram para despertar esse desejo pelo ensino-aprendizagem. Por isso, esses conceitos serão abordados na primeira parte deste estudo. Na sequência, a metodologia será apresentada e três excertos, extraídos da elaboração escrita em língua inglesa dos alunos do $8^{\circ}$ ano, serão analisados por categorias enunciativo-discursivo-linguísticos propostas por Liberali (2013 apud VENDRAMINI ZANELLA, 2013).

Por último, serão tecidas reflexões acerca da produção de significados gerada pelas elaborações dos alunos.

\section{A proposta de ensino-aprendizagem por meio da Atividade Social: participar de um Pen-pal.}

O conceito de ensino-aprendizagem por meio de Atividade Social (LIBERALI, 2009) consiste na intenção de afastar o ensino dos modelos normativos (mecânica, com foco na gramática isolada e dissociada) e de funções (comunicativo, mas com situações práticas e fechadas) e aproximá-lo do ensino de tipos textuais (reconhecimento de gêneros narrativos, descritivos e argumentativos) juntamente com atividade social (necessidade e atividade social, desenvolvimento e vida cotidiana). 
O uso de atividades sociais no ensino de Língua Estrangeira, especificamente, "focaliza o estudo das atividades em que os sujeitos estão em interação com outros em contextos culturais determinados e historicamente dependentes" (LIBERALI, 2009, p. 12), ou seja, os sujeitos trabalham em conjunto para atingir um objetivo que satisfaça alguma necessidade específica da comunidade. Para que seja funcional, é necessário que a atividade social contenha: sujeito, comunidade, divisão de trabalho, objeto, regras e instrumentos no momento de sua elaboração e planejamento.

De forma resumida, a proposta de ensino-aprendizagem por meio da Atividade Social: participar de um Pen-pal tem como objetivo principal colocar os alunos em contato direto com a língua estrangeira por meio de um site/blog no estilo PEN-PAL, cujo tema está de acordo com a Proposta Curricular do Estado de São Paulo (SEE, 2008) do $8^{\text {o }}$ ano, aproximando assim o idioma do cotidiano do aluno. Segue o triângulo ilustrativo da Atividade Social: participar de um PEN-PAL:

Sujeitos: Alunos do $8^{\circ}$ ano e voluntários.

Regras: Participação, engajamento e comprometimento com o projeto. Respeito para com todos os envolvidos.
Instrumentos: Língua Inglesa; Email, youtube, vídeos, projetor, conversas para a produção dos vídeos, fotos e textos. Conversas para reflexão sobre os vídeos, fotos e emails enviados para o site pelos alunos e voluntários. Gêneros orais e escritos. Ambiente multimodal.

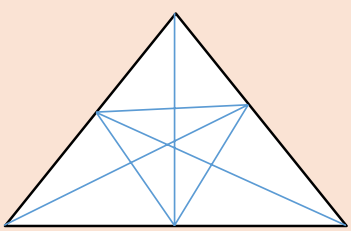

Objetivo: Aproximar a língua estrangeira do cotidiano do jovem. Proporcionar um contato estrangeiro direto para o jovem.
Comunidade: supervisora, educadoras, alunos do $8^{\text {o }}$ ano, educadora coordenadora, jovens estrangeiros voluntários.
Divisão de trabalho: As educadoras e supervisora: selecionam o material a ser explanado, postam o conteúdo recolhido em sala e entram em contato com os voluntários. Alunos do $8^{\circ}$ ano: escrevem textos.

Figura 1: Representação da proposta de ensino-aprendizagem por meio da Atividade Social: participar de um Pen-pal (LIBERALI, 2009). 
A proposta de ensino-aprendizagem por meio da Atividade Social: participar de um PEN-PAL objetiva possibilitar aos alunos o contato direto com a língua estrangeira por meio de um site/blog. A partir das interações e por meio de tecnologia, busca-se compreender se os alunos conseguem entender com mais facilidade o novo idioma e se o desejo pelo ensino-aprendizagem aumenta quando o currículo escolar é trabalhado de forma mais próxima ao cotidiano do jovem.

Os textos em língua inglesa elaborados pelos alunos são parte das atividades solicitadas pela proposta de ensino-aprendizagem discutida neste estudo e podem apresentar produção de significado.

De acordo com Vygotsky (1930/1987), a produção de significado é uma unidade que se associa à vida sócio-histórico-cultural do sujeito. Dessa forma, a linguagem colabora para a reestruturação e funcionamento da consciência sendo, assim, na elaboração oral e escrita do indivíduo. Portanto, a produção de significado dos alunos dependerá da forma como organizam o uso da linguagem.

Nesse enquadre, este trabalho procura constatar a produção de significados na elaboração escrita dos alunos do $8^{\circ}$ ano durante a aplicação da proposta de ensino-aprendizagem por meio da Atividade Social: participar de um Pen-pal.

\section{Protagonismo juvenil.}

Outro conceito importante para o desenvolvimento do projeto é sobre o aluno protagonista. Segundo Costa (2000), defensor e colaborador dessa concepção, pretende-se enxergar o jovem não como problema e sim como parte da solução, ou seja, tornar o adolescente parceiro na solução de problemas da educação e também em outros campos que saiam do âmbito privado para o 
bem comum. A proposta é fazer com que o protagonismo juvenil estimule o desejo dos alunos pela participação social, contribuindo não apenas com o desenvolvimento pessoal, mas com o desenvolvimento das comunidades em que os indivíduos estão inseridos. Dessa maneira, o protagonismo juvenil contribui para a formação de cidadãos mais autônomos e comprometidos socialmente, com valores de solidariedade, sociedade e respeito mais incorporados, o que contribui para uma proposta de transformação social.

A ideia de protagonismo parte de duas perguntas básicas: Que tipo de ser humano se pretende formar? Que sociedade queremos construir? (COSTA, 2000). Com base na sociedade pós-moderna atual, Costa (2000) discute essas questões e explica que, conforme a sociedade evolui com a globalização, o mercado de trabalho torna-se mais competitivo e complexo, a relação entre jovens e adultos torna-se distante, já que as realidades são muito divergentes e os valores como solidariedade, respeito e autonomia vão desaparecendo. Por isso, sugere-se que o adolescente seja parceiro, considerando-se além da transmissão de conhecimento e que o educador apresente-se como fonte para esse saber em que ambos possam viver os valores e ensino-aprendizagem de forma conjunta (COSTA, 2000).

Com isso, o modelo pautado em protagonismo juvenil está de acordo com as propostas das escolas de ensino integral, uma vez que o aluno é visto como fonte autêntica de iniciativa e liberdade. Ainda, esse aluno caracteriza-se pela autonomia para desenvolver seu projeto de vida e participar de forma ampla de todas as questões escolares, como as eletivas, clubes, conselho de classe, etc. Indubitavelmente, tal modelo também foi essencial para a aplicação do "Projeto Pen-pal" de forma que os alunos puderam dar sugestões e até mesmo modificar a ideia inicial juntamente com esta educadora e a supervisora.

\section{A Atividade criadora e a imaginação.}


A elaboração desse projeto também esteve fundamentada pelo conceito de Vygotsky sobre o brincar como atividade criadora (HOLZMAN, 2009). A atividade criadora ou criatividade foi conceituada por Vygotsky (1930/1987) como:

toda realização humana criadora de algo novo, quer se trate de reflexos de algum objeto do mundo exterior, quer de determinadas construções do cérebro ou do sentimento, que vivem e se manifestam apenas no próprio ser humano (VYGOTSKY, 1930/1987, p. 3).

Para o processo criativo, segundo Vygotsky (1930/1987), o cérebro utiliza duas estratégias básicas: 1) atividade reprodutiva e 2) atividade criadora. O primeiro é estreitamente vinculado à memória, pois reproduz atos de uma experiência anterior. Já o segundo é intimamente relacionado à imaginação, a qual parte de elementos formados pela impressão pessoal dos fatos e vivências.

A imaginação é entendida, comumente, como qualidade exclusiva de crianças ou como um talento especial para poucos. Porém ela não é um talento ou uma pré-disposição dos sujeitos, e sim uma característica humana presente em todas as fases da vida e que deve ser estimulada ao longo da trajetória do indivíduo. Tal estímulo é necessário, pois a criatividade manifesta-se de forma diferente em crianças e adultos. Nas crianças, a atividade imaginativa é mais próxima da fantasia, do irreal, subjetiva. Em contrapartida, devido a maiores experiências e interesses, os adultos conseguem transformar a fantasia em algo produtivo e concreto, de forma mais objetiva.

A distância entre a imaginação fantasiosa e a produtiva começa a reduzir quando o sujeito entra na puberdade, pois a razão torna-se mais próxima dos interesses do que a fantasia. Devido a essa reestruturação da imaginação subjetiva para a objetiva e as demais crises emocionais, psicológicas e hormonais em que se encontra o adolescente, o indivíduo tende a perder a 
confiança no produto que isso origina. Por esse motivo, é necessário que haja estímulos externos para incentivar a continuidade da produção criativa.

Vygotsky (1930/1987) esclarece que é exatamente a atividade criadora que faz com que os homens possam projetar-se no futuro, transformando a realidade e modificando o presente. Além disso, o brincar estimula a criatividade e o brincar auxilia a interiorização no ensino-aprendizagem. Por esses motivos, o brincar como estímulo para atividade criadora foi escolhido como base teórica para o projeto desenvolvido.

\section{Procedimentos metodológicos.}

No presente artigo, discute-se uma proposta de ensino-aprendizagem por meio da Atividade Social: participar de um Pen-pal elaborada por esta educadora, sob orientação da coordenadora do projeto PIBID-LI/UNISO. O Projeto PIBID direciona a formação de educadores de modo crítico-colaborativo, em Pesquisa Crítica de Colaboração (PCCol) pois, nesse conceito teórico metodológico, destaca-se a importância do trabalho em grupo para que o trabalho individual seja potencializado (MAGALHÃES, 2009).

O convívio de um grupo, focado em um mesmo objetivo, origina entusiasmo e estimula os participantes a promover um melhor desempenho individual, possibilitando melhores resultados (MARX, 1890/1980, apud FUGA, 2009). No que se refere à formação de educadores, a PCCol contribui para a contínua atividade educativa do educador, debatendo e resolvendo questões conflitantes de forma colaborativa. No caso do PIBID-LI/UNISO, as produções dos educadores e dos formadores, e os debates acontecem nas reuniões de formação, que ocorrem quinzenalmente. 
Ainda, a escolha teórico-metodológica PCCol elege a linguagem como fundamental "para criação, análise, compreensão e interpretação da realidade escolar", oferecendo importante instrumento para o trabalho a todos os envolvidos com o contexto escolar (LIBERALI, 2013, p.111-112). Nessa direção, a linguagem é essencial neste trabalho para analisar a produção de significados na elaboração escrita em língua inglesa dos alunos de $8^{\circ}$ ano.

\subsection{Descrição do contexto.}

A ideia de elaborar a proposta de ensino-aprendizagem por meio da Atividade Social: participar de um Pen-pal surgiu após a coordenadora exibir, em uma das reuniões de formação, um vídeo intitulado "Pupils' views, from Réthymno to the world!" (DIGITMED - Brasil, 20144), no qual adolescentes gregos demonstravam, de forma multimodal, como realmente é o cotidiano em uma escola pública na Grécia.

Como o vídeo surgiu após a problematização da supervisora acerca da necessidade do uso dos netbooks pelos alunos do $8^{\circ}$ ano, decidi apresentá-lo em um blog. Optei por não utilizá-lo no domínio original, pois segundo Moran (1995), o uso de vídeos em sala de aula é benéfico para a aproximação com o cotidiano do aluno, das linguagens e comunicação da sociedade urbana, mas em contrapartida também está:

\footnotetext{
umbilicalmente ligado à televisão e um contexto de lazer, e entretenimento que passa imperceptivelmente para a sala de aula. Vídeo, na cabeça dos alunos, significa descanso e "não aula", o que modifica a postura, as expectativas em relação ao seu uso (MORAN, 1995).
}

Pelos motivos citados acima, decidi dissociar todo e qualquer conteúdo de seu site original para que não houvesse atrativos externos. Com isso,

\footnotetext{
${ }^{4}$ Organizado e desenvolvido por Fernanda Liberali

https://digitmed.wordpress.com/universities/pucsp/fernanda-liberali/
} 
pesquisei na internet possíveis domínios para montar um website ou blog, encontrei uma página que possibilita a produção gratuita de um site de maneira simplificada, rápida e com um design mais atraente (wix.com).

A supervisora comentou com os alunos do $8^{\underline{o}}$ ano sobre a existência do vídeo antes de apresentá-lo em sala de aula, portanto eles imaginaram como poderia ser a Grécia antes de visualizarem o conteúdo. Esse detalhe foi imprescindível para que o engajamento dos alunos fosse satisfatório, pois a imaginação despertou curiosidade e desejo de conhecer a cultura que seria apresentada.

No dia da apresentação do vídeo, primeiramente, enunciamos a seguinte pergunta: "Como vocês imaginam a Grécia?". Pedimos para que eles escrevessem suas opiniões em um papel. De forma geral, as respostas não saiam do senso comum (que o traje típico é a toga, folhas de louro na cabeça e as escolas ao ar livre). Uma questão interessante é que a maioria também acreditava que os gregos não aprendiam a disciplina de história na escola, já que a história, para os alunos do $8^{\circ}$ ano, originou-se naquela região. Havia também um consenso em relação à questão econômica: tinham convicção que todos os gregos, de maneira geral, eram de classe social alta.

Após exibirmos o vídeo, os alunos reescreveram as impressões sobre a Grécia e o povo grego. Demos início à discussão e temas relevantes surgiram a partir das falas dos alunos, inclusive sobre como a língua inglesa nos conecta com o mundo. Os educadores e os alunos tinham consciência da extensão mundial da internet, mas não associavam a maior abrangência que isso poderia ter concomitante ao uso da língua estrangeira.

A expansão de conhecimentos que a língua inglesa pode nos proporcionar pela aproximação com o mundo através da internet entusiasmou os adolescentes e eles se propuseram a entrar em contato com pessoas de outros países. Durante o debate a respeito do vídeo, os alunos problematizaram e 
criticaram a visão que os estrangeiros podem apresentar do Brasil. Com isso, decidiram produzir uma carta contando sobre o cotidiano do brasileiro. Da mesma forma que seus preconceitos sobre os gregos foram esclarecidas, poderiam modificar a representação que o estrangeiro apresentasse sobre o Brasil.

Ao assistir ao vídeo como recorte de uma realidade, os alunos puderam envolver-se sensorialmente com o mundo externo e perceber o "outro" de forma mais ampla que anteriormente (MORAN, 1995). Dessa forma, o vídeo possibilitou o desenvolvimento crítico do jovem. Assim, o imaginar e o pensamento anterior ao vídeo tornam-se caminhos percorridos para o argumento crítico conquistado.

Como os alunos expressaram o desejo de escrever a carta, a supervisora explicou o gênero carta e aplicou diversas atividades relacionadas ao tema. Devido a isso, a supervisora sugeriu que mostrássemos uma carta de participação de pen-pal como exemplo para os alunos. Mediante a solicitação, entramos em contato por email com S., uma adolescente californiana que visitou o Brasil durante a copa do mundo. A estrangeira, S., voluntariamente, escreveu para os alunos do $8^{\mathrm{o}}$ ano contando sobre sua vida na Califórnia, o que gostava sobre o Brasil e seus hobbies. Além disso, a voluntária também enviou fotos de seu quarto, da escola pública que frequentava e do time de futebol de sua cidade.

Na sequência, postei o email com as fotos enviadas pela estrangeira no ambiente multimodal. Ao apresentarmos o texto, notamos grande empolgação e desejo em produzir uma carta-resposta para a voluntária. $\mathrm{O}$ fato de ela conhecer o Brasil fez com que surgissem diversos assuntos relacionados às condições de vida e classes sociais. Os alunos puderam comparar as escolas públicas (Brasil e Califórnia) e as diferentes realidades de classes sociais. 
Após a elaboração em língua inglesa da carta escrita em folha de caderno, os alunos entraram no site e a enviaram por email no espaço destinado a isso dentro do ambiente multimodal. Tais emails foram encaminhados diretamente para o endereço de email desta educadora.

Em seguida, durante a aula do $8^{\mathrm{o}}$ ano, a supervisora fez a correção coletiva dos textos, organizando algumas ideias e explicando a gramática da língua inglesa. Nesse momento, alguns pontos relacionados ao gênero foram enfatizados pela supervisora: a utilização de operadores argumentativos para explicar algo que os alunos gostem, por exemplo, why/porque, because/ porque, and/e, but/mas. Posteriormente, os textos corrigidos foram postados no site e as respostas foram encaminhadas para a voluntária. Assim, finalizou-se o projeto.

\subsection{Os procedimentos de coleta e análise de dados.}

Os excertos aqui estudados advêm da elaboração escrita em língua inglesa dos alunos do $8^{\circ}$. ano de uma escola pública a partir do desenvolvimento de atividades elaboradas por esta educadora no subprojeto do PIBID-LI/UNISO.

Para a análise do excerto, são focalizados aspectos enunciativodiscursivo-linguísticos com base na perspectiva de argumentação, proposta por Liberali5 $^{5}$ (2013, apud VENDRAMINI ZANELLA, 2013) apontados por categorias analíticas: como abertura, pergunta retórica, apresentação de ponto de vista, de explicações e de justificativas entre outras. Essas categorias revelam o modo pelo qual os alunos utilizam a linguagem e produzem significados na elaboração oral e escrita.

Das questões enunciativas são discutidos o local e momento de produção/recepção/circulação e o papel social dos interlocutores na produção

\footnotetext{
${ }^{5}$ As categorias argumentativas propostas por Liberali (2013 apud Vendramini Zanella, 2013) estão fundamentadas nas pesquisas de Bronckart (1997/1999), Dolz e Schneuwly(2004), Perelman e Tyteca (1958/2005), entre outros. Também, essas categorias pautam-se em uma visão dialógica de linguagem, dos ensinamentos bakhtinianos (Bakhtin/ Volochinov, 1929/ 2010 apud Vendramini Zanella, 2013).
} 
das experiências. Em relação às questões discursivas, a organização e a articulação do texto escrito em língua inglesa são analisadas. Quanto às questões linguísticas, busca-se pelas escolhas lexicais e operadores argumentativos encontrados no trabalho de Koch (2010) e também Liberali (2013) (ambas obras apud VENDRAMINI ZANELLA, 2013) para se constatar a produção de significados dos alunos do $8^{o}$ ano acerca de suas apropriações em língua inglesa e sobre as características da carta para participar de um pen-pal. Além disso, interpreta-se a produções de significados dos alunos mediante a discussão de conceitos do protagonismo juvenil (SEE, 2012) e da atividade criadora (VYGOTSKY, 1930/ 1987).

Por último sobre a análise, os nomes dos alunos e da voluntária estrangeira que aparecem no recorte são substituídos por suas iniciais.

\subsection{Análise e discussão.}

Como já mencionado, as produções escritas em língua inglesa originaram-se após aplicação da proposta de ensino-aprendizagem por meio da Atividade Social: participar de um Pen-pal.

No primeiro excerto, apresenta-se o email da voluntária estrangeira S. encaminhado a esta educadora e, na sequência, as respostas dos alunos para a S.. Vale lembrar que S. é a adolescente californiana que colaborou para a aplicação do "Project Pen-pal" enviando um email com suas informações pessoais e hobbies.

My name is S., I'm 14 years old. I live in Hesperia, California (Abertura). I visited Brazil in July 2014 to the World Cup. I love it! I play soccer since I was 8 and maybe one day I could play professionally, if this happened I want to be selected to play for a Brazilian Team and move to Brazil. (Apresentação de ponto 
de vista) Yes, I really want to live in Brazil. Why? (Pergunta retórica) People in Brazil are always outside and here we are always inside. (explicação à pergunta retórica) I love it! (Apresentação de ponto de vista) Nice to meet you! Xoxo, S.

Hey S.! My name is B. H., I am 13 years old and in the future I want to be an architect. My favorite song is "All that matters Justin Bieber" and my favorites Television series is Supernatural and Dr. House. I like to play video game, read and stroll with my friends. (Apresentação de ponto de vista sem explicações e justificativas). Nice to meet you! (EXCERTO1)

A mensagem da pen-pal S. é organizada por abertura, desenvolvimento e conclusão e articula-se por meio de apresentação de ponto de vista, pergunta retórica seguida de explicação, demarcada pelo uso do operador argumentativo "why" / "Por quê?".

Ainda, observa-se que o papel social da interlocutora é de uma adolescente, estrangeira, falante de língua inglesa que visitou o Brasil recentemente e que deseja jogar futebol e morar no Brasil. Essas questões podem ser verificadas pelas escolhas lexicais: "Hesperia", "California", "visited" / "visitei", "love" / "amo", "play soccer"/ "jogo futebol", "play professionally"| "Jogar profissionalmente", "live in Brazil"| "morar no Brasil". Em uma visão vygotskyana, isso implica na atividade criadora de S. que vivenciou a cultura de país diferente do seu, no caso o Brasil, e agora planeja seu futuro como em "I really want to live in Brazil", buscando transformar a realidade.

Na elaboração escrita do aluno B.H., também fica evidente sua atividade criadora (VYGOTSKY, 1930/1987) e o brincar na perspectiva vygotskyana (HOLZMAN, 2009), pois demonstra B.H. imaginando-se como arquiteto.

Essas questões são marcadas pelas escolhas lexicais: "in the future"/ "no futuro", "architect" / "arquiteto", "read"/“ler" - no sentido de enxergar-se no futuro como arquiteto. Além disso, o fato de B. H. gostar de ler e jogar vídeo 
game pode ser um dos estímulos externos para a criatividade de B.H.. Esse brincar e imaginar-se possibilita a interpretação de papéis sociais antes de realmente ter que assumi-los socialmente.

Também, é possível notar no enunciado de B.H. o protagonismo juvenil (SEE, 2012), porque ligado ao conceito de jovem protagonista existe a concepção de projeto de vida, no qual o aluno é incentivado a pensar sobre seu papel social no futuro. A palavra "stroll" / "passear", por ser uma construção lexical diferente, pode ser advinda do constate uso de vídeo games e demonstra o uso real da língua inglesa.

Em contrapartida, na apresentação do ponto de vista de B.H., constata-se a falta de operadores argumentativos, como "because" / "porque" no texto do aluno, que explicassem suas ideias e desejos. $\mathrm{O}$ aluno conseguiria utilizar esses operadores, pois a importância da aplicação dos mesmos havia sido enfatizada pela educadora, supervisora do projeto PIBID-LI/UNISO.

As questões da atividade criadora e protagonismo juvenil permearam outros excertos, como se observa, a seguir:

Hello, my name is M. I'm 14 years old. I love my family, my friends and music. I don't like sports. I'm from Sorocaba, Brazil (Apresentação de ponto de vista). I would like to live in Paris. Do you like football? (Pedido de ponto de vista) I don't like football because I always fell on the floor, I am not too good in sports. (Apresentação de explicação) I think that it's a family thing. I want to be a lawyer. Nice to meet you! (EXCERTO 2)

Neste segundo excerto, pelas escolhas lexicais: "I would like to live in Paris"/ "Gostaria de viver em Paris", "I want to be"/ "Eu quero ser (...)", "laywer" / "advogada" - observa-se a atividade criadora (VYGOTSKY, 1930/1987) em relação a enxergar-se no futuro como advogada, vivendo em Paris. Nota-se o protagonismo juvenil (SEE, 2012), pois há também o papel 
social almejado por M. no futuro. A aluna M. utiliza o operador argumentativo "because" / "porque" para apresentar a explicação sobre o porquê de não gostar dos esportes demonstrando maior domínio da língua inglesa assim, oferecendo sustentação para suas ideias. Contudo, devido à pergunta feita por M. à S. “Do you like football?"| "Você gosta de futebol?" pressupõem-se que a aluna não compreendeu alguma parte do texto enviado pela californiana, uma vez que $S$. já havia afirmado claramente em seu email que joga futebol desde seus 8 anos.

Vale ressaltar a importância do ambiente multimodal envolvido no momento da elaboração de texto em língua inglesa dos alunos, uma vez que, para muitos, o contato com a estrangeira S. tenha possibilitado o ensinoaprendizagem da língua estrangeira. Dessa forma, a partir das interações e por meio de tecnologia, os alunos apropriaram-se de vocabulário mais amplo e conseguiram entender com mais facilidade o novo idioma. Adicionalmente, o desejo pelo ensino-aprendizagem da língua parece aumentar, uma vez que a proposta escolar é trabalhada de forma mais próxima ao cotidiano do jovem.

Em contrapartida, a ansiedade e inquietação para elaborar respostas para S., podem ter causado distração em M..

Hi! My Name is G. H., my nick name's G.. I am 14 years old and I'm from Sorocaba, Brazil. I am a Web Designer. This has always been my life project, it's awesome. My favorite kind of music is RAP. (Apresentação de ponto de vista sem explicação ou justificativa) Ok, I know that's not the best kind of music in the world, but is my style. (Apresentação de ponto de vista com justificativa). My favorite sports are Boxe and Soccer and I'm the goalkeeper. I also practice Skateboarding. I don't have too many things to say about me. (Apresentação de ponto de vista sem explicação ou justificativa) Nice to meet you! Good Bye, G.! (EXCERTO 3)

Neste terceiro excerto, verifica-se a utilização de alguns operadores argumentativos, como "and"/ "e" (de enumeração), "but"/"mas" (de adversativa), que são importantes aspectos linguísticos na produção do gênero 
carta de participação de pen-pal, pois orientam a descrição daquilo que está sendo apresentado. Mas, como o aluno G.H. comentava algo que gostava, poderia ter utilizado o "because" / "porque" para explicar ou justificar seu gosto por "boxe and soccer" / "Boxe e futebol".

Ainda, o aluno G.H. utiliza verbo no tempo presente perfeito, na construção "This has always been my life project"/ "Esse sempre foi meu projeto de vida", a expressão "awesome" / "incrível" e a elaboração "that's not the best kind of music in the world," /"Eu sei que esse não é o melhor estilo de música do mundo" que demarcam que o aluno possui conhecimento da língua inglesa além do básico.

Mais uma vez, pode-se observar a atividade criadora (VYGOTSKY, 1930/1987) e o protagonismo juvenil (SEE, 2012) na elaboração escrita do aluno. No caso de G.H., essas questões materializam-se no apresentar-se como "web designer", possível futuro boxeador e jogador de futebol, goleiro e skatista.

Em síntese, a partir das análises dos três excetos, é possível constatar que os alunos do $8^{\mathrm{o}}$ ano demonstram apropriações iniciais sobre as questões trabalhadas na proposta de ensino-aprendizagem e que assumiram papéis na Atividade Social: participar de Pen-pal.

Além disso, utilizaram a língua inglesa por meio de tecnologia o que orientou melhor o trabalho dos alunos com o novo idioma, possivelmente despertou o desejo pelo ensino-aprendizagem e revelou que o adolescente e o educador podem ser parceiros no ensino-aprendizagem, como sugere Costa (2000).

Finalmente, observa-se que os alunos também produzem significados acerca do protagonismo juvenil e atividade criadora pelas escolhas lexicais em suas elaborações escritas.

\section{Conclusão}


Este trabalho objetivou analisar a produção de significado na elaboração escrita em língua inglesa dos alunos de uma escola pública a partir do desenvolvimento de atividades elaboradas por esta educadora no subprojeto do PIBID-LI/UNISO.

Para tanto, analisou-se três excertos advindos da elaboração escrita em inglês dos alunos do $8^{\mathrm{o}}$ ano de uma escola pública, a partir de categorias argumentativas que centralizavam os aspectos enunciativo-discursivolinguísticos e interpretados mediante o aporte teórico apresentado neste trabalho. Assim, a produção de significados realizou-se pela maneira que os alunos, como sujeitos sócio-histórico-culturais (VYGOTSKY, 1930/1987), organizaram o uso da linguagem em suas elaborações escritas.

A análise aponta algumas dificuldades enfrentadas no processo, como o de não explicar ou sustentar o ponto de vista na elaboração escrita mesmo que a supervisora houvesse enfatizado a importância do uso de operadores argumentativos na correção dos textos escritos.

Apesar dessas dificuldades, alguns pontos favoráveis foram constatados, como o de vivenciar a Atividade Social: participar de um Pen- pal. Os alunos tiveram, nessa Atividade Social, a possibilidade de brincar, imaginar-se, assumir papéis e desejar comunicar-se em língua inglesa. Com isso, também produziram significados sobre o protagonismo juvenil (SEE, 2012) e atividade criadora (VYGOTSKY, 1930/ 1987).

Por último, a partir dessa experiência, foi possível desenvolver uma maior vivência da língua inglesa e promover interesse no ensino-aprendizagem. Concomitante a essa aproximação com a cultura estrangeira, os alunos utilizaram instrumentos multimodais que possibilitam que o estudo de língua 
inglesa torne-se mais atrativo, por despertar desejos e aproximá-los a suas realidades.

\section{REFERÊNCIAS}

BRASIL. Secretaria de Educação Fundamental. Parâmetros curriculares nacionais: terceiro e quarto ciclos do ensino fundamental: língua estrangeira / Secretaria de Educação Fundamental. Brasília: MEC/SEF, 1998.

BAKHTIN, M. M. / VOLOCHINOV, V. N.. Marxismo e filosofia da linguagem: problemas fundamentais do método sociológico na ciência da linguagem. 14 $4^{\mathrm{a}}$ ed. Trad. Michel Lahud e Yara Frateschi Vieira. São Paulo: HUCITEC, 2010 [1929].

BRONCKART. J. P.. Atividade de linguagem, textos e discursos: por um interacionismo sócio discursivo. São Paulo: EDUC, 1997/1999.

CAMBRIDGE DICTIONARY, 2015._http://dictionary.cambridge.org/us/_Acesso em: Janeiro, 2015.

COSTA, A. C. G. da. Protagonismo Juvenil: O que é e como praticá-lo? Publicação em Instituto Aliança, 2000. http://www.institutoalianca.org.br/Protagonismo_Juvenil.pdf Acesso em: Dezembro, 2014.

DIGITMED, New movie by pupils in Greece, postado em 23 Janeiro de 2014. https://digitmed.wordpress.com/2014/01/23/new-movie-by-pupils-in-greece Acesso em Maio, 2014.

FUGA, V. P.. O Movimento do Significado de Grupo de Apoio na Cadeia Criativa de Atividades no Programa Ação Cidadã. Tese de Doutorado em Linguística Aplicada e Estudos da Linguagem. Pontifícia Universidade Católica de São Paulo, 2009.

HOLZMAN, L.. Vygotsky at work and play. New York: Routledge, 2008.

KOCH, I. V.. A Inter-ação pela linguagem. 10ạ. edição. São Paulo: Contexto, 2010. 
LIBERALI, F. C. Argumentação em Contexto Escolar. Campinas, SP. 2013.

LIBERALI, F. C. Atividade social nas aulas de língua estrangeira. São Paulo: Ed. Richmond, 2009.

MARX, K. O Capital: critica da economia política - volume I. 5a edição. Tradução:

Reginaldo Sant’ Anna. Rio de Janeiro: Civilização Brasileira, S.A, 1890/1980.

MARX, K.; ENGELS. F. A Ideologia alemã: teses sobre Feuerbach. São Paulo:

Centauro Editora, 2006. [1845-46]

MAGALHÃES, M. C. C.. O método para Vygotsky: a zona proximal de desenvolvimento como zona de colaboração e criticidade criativas. In: SCHETTINI, R. H. et. al..; (orgs.) Vygotsky: uma revisita no início do século XXI. São Paulo: Andross. 2009, p. 53-78.

MORAN, J. M.. O vídeo na sala de aula. Revista Comunicação \& Educação. ECA, São Paulo - Ed. Moderna, [2]: 27 a 35, jan./abr. de 1995.

PERELMAN, C.; TYTECA, L. O.. (1958) Tratado da Argumentação: A Nova Retórica. Trad.: Maria Ermantina de Almeida Prado Galvão. São Paulo: Martins Fontes, 2 ${ }^{\mathrm{a}}$ ed, 2005.

SEE, Secretaria da Educação. Proposta Curricular do Estado de São Paulo: Inglês/ Coord. Maria Inês Fini. - São Paulo: SEE, 2008.

SEE. Diretrizes do Programa de Ensino Integral. São Paulo: SEE, 2012. $<$ http://www.educacao.sp.gov.br/a2sitebox/arquivos/documentos/342.pdf Acesso em 13/06/2014.

SCHNEUWLY, B., DOLZ, J. et al. Gêneros orais e escritos na escola. Campinas: Mercado de Letras, 2004, p. 41-70.

VENDRAMINI ZANELLA. D. A.. Por uma formação crítico-criativa de alunasprofessoras e professora-pesquisadora na graduação em Letras. 2013. Tese (Doutorado em Linguística Aplicada e Estudos da Linguagem) - Pontifícia Universidade Católica de São Paulo, 2013.

VYGOTSKY, L. S.. 1930. Imaginacion y el arte em la infancia. Mexico: Hispânicas, 1987. 
Revista Letras Raras

ISSN: 2317-2347 - Vol. 7, Ano 4, No 2 - 2015

Recebido: em 28 de agosto de 2015 Aceito para publicação: 24 de outubro de 2015 